Sustentare, Três Corações, v. 1, n. 1, p. 1-17, ago./dez. 2017

\title{
APLICAÇÃO DO MODELO DE GESTÃO DE DRENAGEM URBANA (SWMM) NA SUB- BACIA 2 DA ESTRADA NOVA EM BELÉM DO PARÁ
}

\author{
Narjara Rúbia Lima da SILVA ${ }^{1}$; Marco Valério de Albuquerque VINAGRE ${ }^{2}$; Leonardo Augusto \\ Lobato BELLO ${ }^{3}$; Mariane de Andrade CUNHA ${ }^{4}$
}

\author{
${ }^{1}$ Engenheira Civil (UFPA). Mestranda em Desenvolvimento e Meio Ambiente Urbano (UNAMA). E-mail: \\ narjararubia@hotmail.com. \\ 2 Engenheiro de Infraestrutura (ITA). Doutor em Engenharia de Recursos Naturais (UFPA). Professor Titular da Universidade da \\ Amazônia (UNAMA). E-mail: valeriovinagre@gmail.com. \\ ${ }^{3}$ Engenheiro Civil (UNAMA). Doutor em Engenharia Civil - Geotecnia (PUC-RIO). Professor Titular da UNAMA e coordenador \\ do Programa de Mestrado em Desenvolvimento e Meio Ambiente Urbano da UNAMA. E-mail: lalbello1402@gmail.com. \\ ${ }^{4}$ Engenheira Sanitarista e Ambiental (UNAMA). E-mail: marianedcunha@gmail.com
}

Recebido em: 10/05/2017 - Aprovado em: 10/07/2017 - Disponibilizado em: 30/12/2017

RESUMO: O crescimento populacional desordenado observado na cidade de Belém, com a ocupação sem planejamento em áreas vulneráveis da cidade, se refletiu em problemas de drenagem pluvial urbana, resultando em inundações nas áreas habitadas. $\mathrm{O}$ presente artigo apresenta um estudo realizado com o objetivo de contribuir para o planejamento e gestão da drenagem pluvial urbana de Belém-PA, com a simulação de três cenários de escoamento da rede de macrodrenagem da Sub-Bacia 2 da Estrada Nova, utilizando o código computacional livre Modelo de Gestão de Drenagem Urbana (Storm Water Management Model - SWMM). O evento climático da simulação foi uma chuva intensa ocorrida em 09 de maio de 2011, com índice pluviométrico de $61 \mathrm{~mm}$ e duração de três horas. O primeiro cenário consiste no canal com o projeto parcialmente executado. O segundo cenário com o canal projetado e implantado sem bacia de acumulação. O terceiro cenário com o projeto completamente implantado e com bacia de acumulação. Assim verificou-se a ocorrência de transbordamentos e enchentes em pontos críticos; indicando a utilidade de mais estudos da SubBacia 2 da Estrada Nova em Belém-PA.

Palavras-Chave: Ocupação Desordenada. Inundação. Drenagem Pluvial. Rede de Macrodrenagem.

\section{APLICATION OF THE STORM WATER MANAGEMENT MODEL (SWMM) IN SUB- BASIN 2 OF ESTRADA NOVA IN BELÉM DO PARÁ}

\begin{abstract}
The disordered population growth observed in the city of Belém, with unplanned occupation in vulnerable areas of the city, was reflected in urban storm drainage problems, resulting in flooding in the inhabited areas. The present article presents a study carried out with the objective of contributing to the planning and management of urban stormwater drainage in Belém-PA, with the simulation of three scenarios of drainage of the macro-drainage network of Sub-Basin 2 of Estrada Nova, using the computational code Free Model of Storm Water Management Model (SWMM). The climatic event of the simulation was an intense rain that occurred on may 9,2011, with a rainfall of $61 \mathrm{~mm}$ and a duration of three hours. The first scenario consists of the channel with the project partially executed. The second scenario with the channel designed and deployed without accumulation basin. The third scenario with the project completely implanted and with accumulation basin. Thus, the occurrence of floods and floods at critical points; indicating the usefulness of further studies of Estrada Nova Sub-Basin 2 in Belém-PA.
\end{abstract}

Keywords: Messy Occupation. Inundation. Rain Drenage. Macrodain Network.

\section{INTRODUÇÃO}

O crescimento acelerado da população brasileira, principalmente nas regiões metropolitanas, causou uma ocupação desordenada nas cidades, comprometendo o equilíbrio das mesmas. Sendo que, segundo a Constituição Federal de 1988, Art. 225, todos têm direito ao meio ambiente ecologicamente equilibrado, bem de uso comum do povo e essencial à sadia qualidade de vida, impondose ao Poder Público e à coletividade o dever de defendê-lo e preservá-lo para as presentes e futuras gerações. Logo, é dever do Poder Público realizar a gestão do meio ambiente urbano de modo competente e sustentável, adequado para que se tenha um meio 
ambiente equilibrado.

Principalmente nas metrópoles, o desequilíbrio ambiental urbano ocasiona diversos problemas, como no caso de Belém, capital do Estado do Pará, onde ocorre a ocupação por moradores de áreas de mananciais e ambientalmente frágeis, caracterizadas como áreas de risco; a alta taxa de impermeabilização do solo urbano, resultando em um aumento da velocidade de escoamento superficial e assoreamento dos rios; além das enchentes que ocorrem pelos dois processos, tanto naturais quanto de urbanização.

A inadequada ocupação territorial urbana, sem o devido planejamento integrado das diversas infraestruturas necessárias ao desenvolvimento harmônico da cidade, desencadeou o surgimento de problemas de drenagem por ocasião dos eventos hidrológicos de alta intensidade (RIGHETTO, 2009).

Tendo em vista os diversos problemas de drenagem ocasionados por um conjunto de fatores ineficientes ou de origem natural como as chuvas intensas, necessita-se de estudos a fim de diminuir os danos e gerar soluções para que tais acontecimentos não ocorram novamente. Por isso, os estudos das bacias hidrográficas têm sido cada vez mais importantes, por desenvolverem novos métodos que reduzam os problemas gerados por essa ocupação desordenada e sem o devido planejamento correto na maioria das cidades.
Tem-se entre os métodos, os modelos de chuva-vazão, onde há o propósito de estimar o deflúvio em um sistema de drenagem qualquer, produzido por um evento de chuva intensa, os quais buscam reproduzir as fases do ciclo hidrológico entre a precipitação e o escoamento do ponto específico de interesse, a fim de se aproximar de resultados reais.

Há diversos modelos que se pode trabalhar para alcançar cenários diferentes, possibilitando estratégias de mudanças e eficiência para um sistema de drenagem. Entre eles, no qual o presente estudo se refere, a modelagem hidrológica. Uma das finalidades desse tipo de modelagem e da qual o estudo tem o objetivo, é de submeter simulação de vazões em cursos de águas de bacias hidrográficas, pois suas características sofrem intervenções ao longo do tempo, sempre estando em processo de alteração e precisando de análises, por ocasionarem enchentes, por exemplo, principalmente quando há uma densa população ao redor da mesma, interferindo de outras maneiras que não sejam apenas naturais.

O reflexo na cidade da incompatibilidade entre o urbanístico e a hidrologia está em áreas que acumulam as águas provenientes das precipitações, causando enchentes. Em Belém do Pará, os principais fatores relacionados a esses problemas são a forma como se processou a ocupação urbana e o grande índice de pluviometria (LIMA, 2004). 
Assim, notando-se no dia-a-dia da cidade de Belém, na qual ocorrem frequentes alagamentos, que o presente estudo sobre a Bacia Hidrográfica da Estrada Nova, mais precisamente a Sub-bacia 2 da Estrada Nova, com a utilização de um software livre de modelo de chuva-vazão, mais especificamente, o SWMM - Storm Water Management Model mostra-se valioso, pelas efetivas contribuições ao planejamento e à gestão da drenagem pluvial urbana que o presente trabalho traz.

O planejamento urbano define os espaços e a densidade de ocupação que se reflete na demanda de água, na produção de esgoto, na geração de resíduos sólidos e impermeabilização do solo que afeta a gestão da drenagem urbana (TUCCI, 2012).

A expansão urbana no Brasil ocorre de diferentes formas, tanto pelo modo territorial como se apresenta cada cidade, podendo a população mais carente se instalar em áreas impróprias, também por ações políticas que levem um número de pessoas a morar em algum local que antes não era frequentado, com projetos específicos de moradias promovidos para habitação dos mesmos. No entanto, é preciso ter um acompanhamento, seja de qual for o processo, a fim de utilizar o Planejamento Urbano para considerar os possíveis cenários diferentes para cada situação. Este processo é acompanhado por ações municipais que usualmente não incluem prevenções contra o impacto sobre a drenagem. Como o país encontra-se num estágio em que não existe regulação no controle da ampliação das vazões de cheia devido à urbanização, a tendência é dos prejuízos aumentarem em taxas exponenciais (TUCCI; MARQUES, 2000).

Segundo Araújo Jr (2013), o uso do solo e ocupação humana intensificados em Belém (PA), fez com que áreas inadequadas fossem utilizadas para moradia. Verificandose que a forma com a qual esses processos se sucederam geraram e ainda geram problemas ambientais na área da Bacia da Estrada Nova.

Araújo Jr (2013) ainda diz que foi constatado que moradias e comércios localizam-se em áreas às margens dos cursos d'água (planícies de inundação), as quais estão sujeitas às marés, onde duas vezes por dia "sobem" (preamar) e "descem" (baixamar) e podem ser intensificadas por conta de marés de sizígia (cheias excepcionais) ou alagamentos devido à pluviosidade (a qual é bastante alta na região durante o ano).

As chamadas "baixadas" de Belém constituem-se por regiões da cidade inseridas abaixo da cota altimétrica quatro metros, que, devido à sua proximidade a cursos d'água, tendem a alagar-se em períodos de maior precipitação ou mesmo em virtude do regime de cheias de um rio próximo. No entanto a consolidação das baixadas como áreas de densa ocupação populacional apresenta-se hoje como um grande fator gerador do problema social que envolve o alagado e as populações de baixa renda (ARAÚJO, 2012).

À medida que a urbanização foi 
modificando a cidade de Belém, com ocupações preferencialmente nas cotas mais altas das cidades, visto que a cidade possuía acidentes hídricos que ao invés de saneá-los, preferiu-se contorná-los, deixando as áreas alagáveis, que possuíam cotas mais baixas, desocupadas. Porém, segundo Brasil (2004), parte da população de menor renda e que precisava se instalar na cidade, passou a ocupar assentamentos diretamente sobre argilas ou suspensas por estacas, as chamadas palafitas em terrenos encharcados permanentemente e para onde se drenava parte dos esgotos das áreas mais altas. Ao longo dos anos, Belém (PA) teve um rápido processo de urbanização, que teve como consequência a excessiva impermeabilização do solo, sendo que as áreas de baixada de Belém também foram sendo apropriadas pela população, de acordo com sua lógica de ocupação intensiva do solo (ARAÚJO, 2012).

Assim, devido à impermeabilização do solo, o volume infiltrado diminuiu e o volume de escoamento superficial aumentou, sobrecarregando canais e rios, e ocasionando diversos problemas sanitários e perdas materiais por parte dos moradores (CUNHA, 2016).

No sistema de drenagem urbana o escoamento de águas pluviais sempre ocorrerá independentemente de existir ou não sistema de drenagem adequado. A qualidade desse sistema é que determinará se os benefícios ou prejuízos à população serão maiores ou menores (SMDU, 2012). O sistema de drenagem determina a qualidade do sistema como um todo, de modo a diminuir os prejuízos devido a alagamentos, cheias e inundações, os quais além de prejuízos materiais contribuem para aumentar o risco de epidemias; diminuir o número de desabrigados, bem como o transtorno de acidentes no trânsito, levando assim à redução de gastos públicos em diferentes setores.

A Figura 1 mostra área de ocupação informal na confluência dos canais da Tv. Dr. Moraes e Av. Generalíssimo Deodoro, na Subbacia 2 da Estrada Nova, em Belém (PA).

Figura 1- Palafitas na Sub- bacia 2 da Estrada Nova.

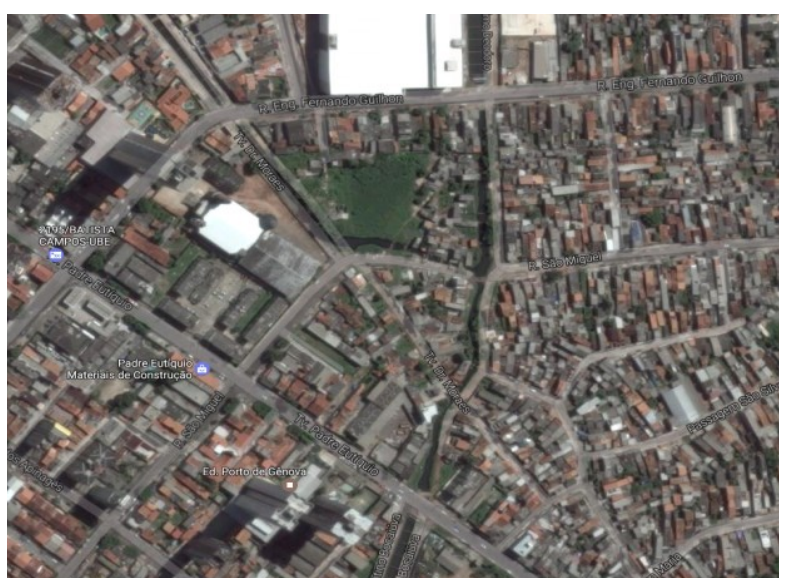

Fonte: Google Earth, 2017.

Observa-se na área mostrada na Figura 1 canais não retificados e com seção reduzida, estrangulando o escoamento.

A Figura 2 mostra residência tipo palafita sobre o canal da Av. Generalíssimo Deodoro, na bacia da Estrada Nova em Belém-PA. 
Figura 2- Palafitas na Sub- bacia 2 da Estrada Nova.

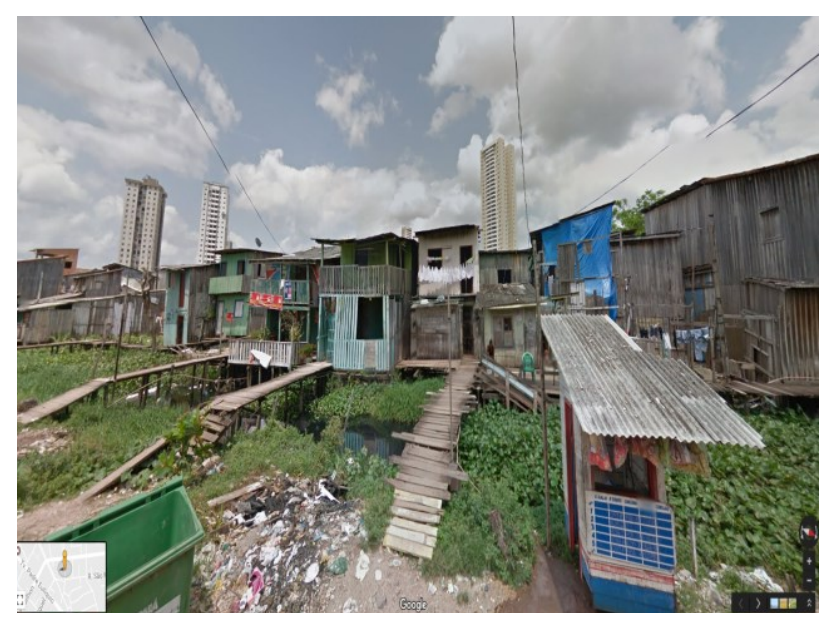

Fonte: Google Earth, 2017.

Segundo Rossman (2010), o Modelo de Gestão de Drenagem Urbana (Storm Water Management Model - SWMM), da Agência Ambiental Americana (Enviroment Protecion Agency - EPA), é um modelo dinâmico chuvavazão que simula a quantidade e qualidade do escoamento superficial, especialmente em áreas urbanas; pode ser utilizado para a simulação de um único evento chuvoso, bem como para uma simulação continua de longo prazo (ROSSMAN, 2010).

O módulo de transporte hidráulico do SWMM simula o percurso destas águas através de um sistema composto por tubulações, canais, dispositivos de armazenamento e tratamento, bombas e elementos de regulação. $\mathrm{O}$ software acompanha a evolução da quantidade e qualidade do escoamento de cada sub-bacia, assim como a vazão, a altura de escoamento e a qualidade da água em cada tubulação e canal, durante um período de simulação composto por múltiplos intervalos de tempo. Assim, cada estudo utiliza as opções desejáveis para se aplicar, com sua determinada finalidade (ROSSMAN, 2010).

O SWMM é o modelo mais utilizado do mundo, pois além de ser um software livre o mesmo permite que o usuário modifique os comandos, devido ter seu código de programação aberto ao longo destes 40 anos. Além da EPA, empresas que trabalham no desenvolvimento de aplicativos já realizaram modificações no SWMM, a maioria promovendo integração com o ambiente SIG ou CAD, incluindo ferramentas de apresentação dos resultados e melhoria na capacidade do banco de dados do aplicativo (PIRES; MACEDO, 2011).

\section{MATERIAL E MÉTODOS}

No presente estudo foi realizada a simulação do comportamento hidrológico da rede de macrodrenagem da Sub-Bacia 2 da Estrada Nova, em Belém (PA), com o auxílio do código computacional livre SWMM, sob o efeito de uma chuva intensa real.

\section{A Bacia Hidrográfica da Estrada Nova}

A Bacia da Estrada Nova, conforme Figura 3, possui área de drenagem de 954 hectares (ha), sendo a quinta maior bacia hidrográfica da cidade, ocupando $16 \%$ da área da malha urbana, abrangendo integralmente os bairros da Cremação, Condor, Jurunas, Guamá e parcialmente os bairros de São Brás, Nazaré e Jurunas (LIMA, 2004). 
Figura 3 - Bacia Hidrográfica da Estrada Nova.

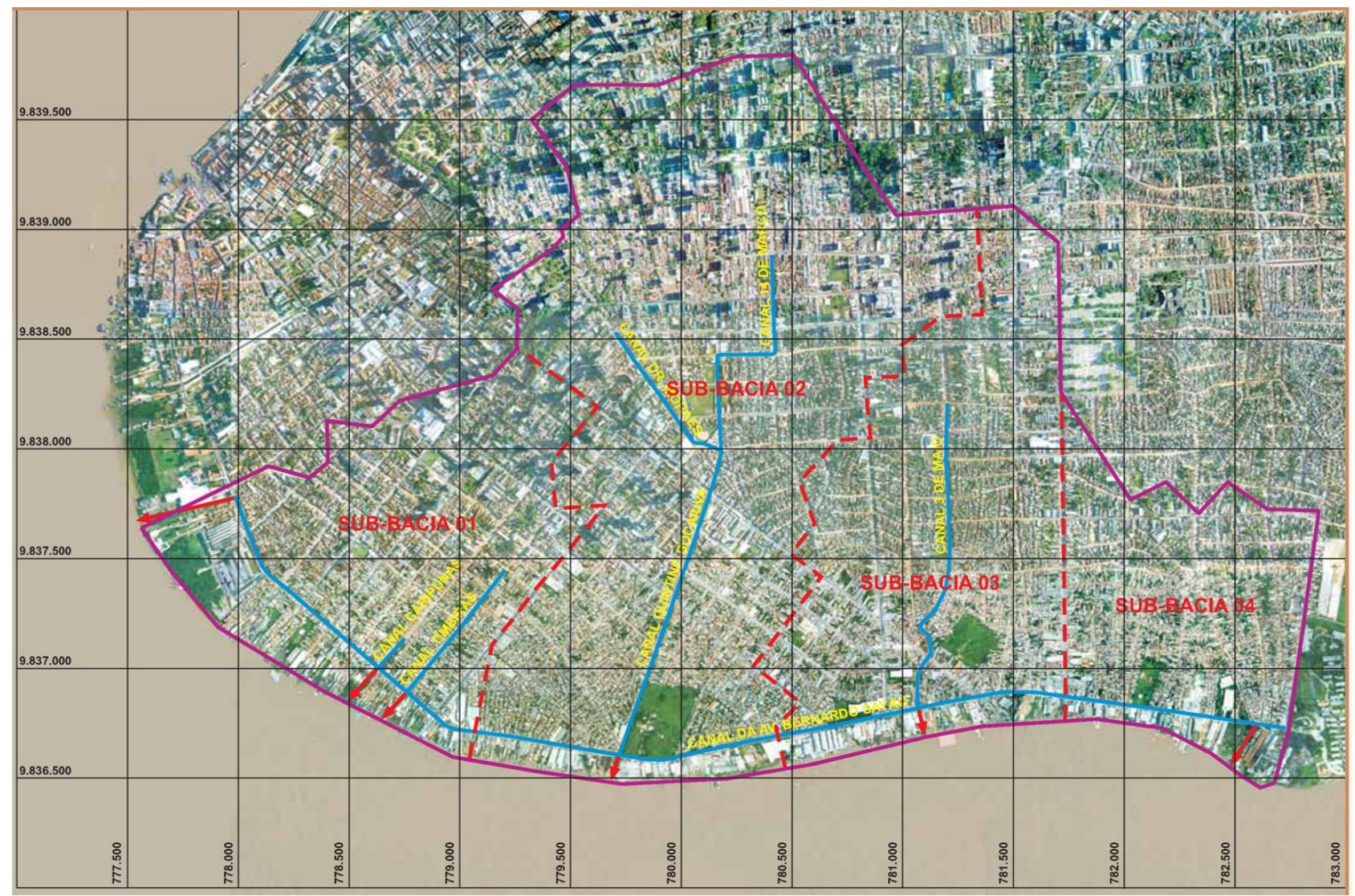

Fonte: ENGESOLO (2008)

elevados níveis de maré (BRAGA, 2014).

A Bacia da Estrada Nova é dividida em quatro sub-bacias.

\section{Sub-Bacia 2 da Estrada Nova (SB2)}

As quatro sub-bacias estão em área predominantemente urbana, com habitações de pequeno porte ocupadas de forma desordenada, principalmente nas margens do rio Guamá e dos igarapés responsáveis pela drenagem e escoamento da bacia hidrográfica, mesmos canais que recebem influência direta das marés. Esse sistema funciona como um grande reservatório quando da concomitância de eventos de precipitação e, por conseguinte geração de escoamento superficial em

A área específica estudada, dentre as quatro sub-bacias, é a sub-bacia 2 (SB2), composta pelos canais das vias: Tv. Dr. Moraes, Av. Generalíssimo Deodoro, Rua dos Caripunas, Tv. Quintino Bocaíuva e Av. Bernardo Sayão. Foi estudada importante melhoria ao projeto (Figura 4), uma bacia de acumulação, na confluência dos canais da Tv. Dr. Moraes e Av. Generalíssimo Deodoro

A Figura 4 mostra as intervenções na sub-bacia 2 da Estrada Nova. 
Figura 4 - Intervenções na Sub-Bacia 2.

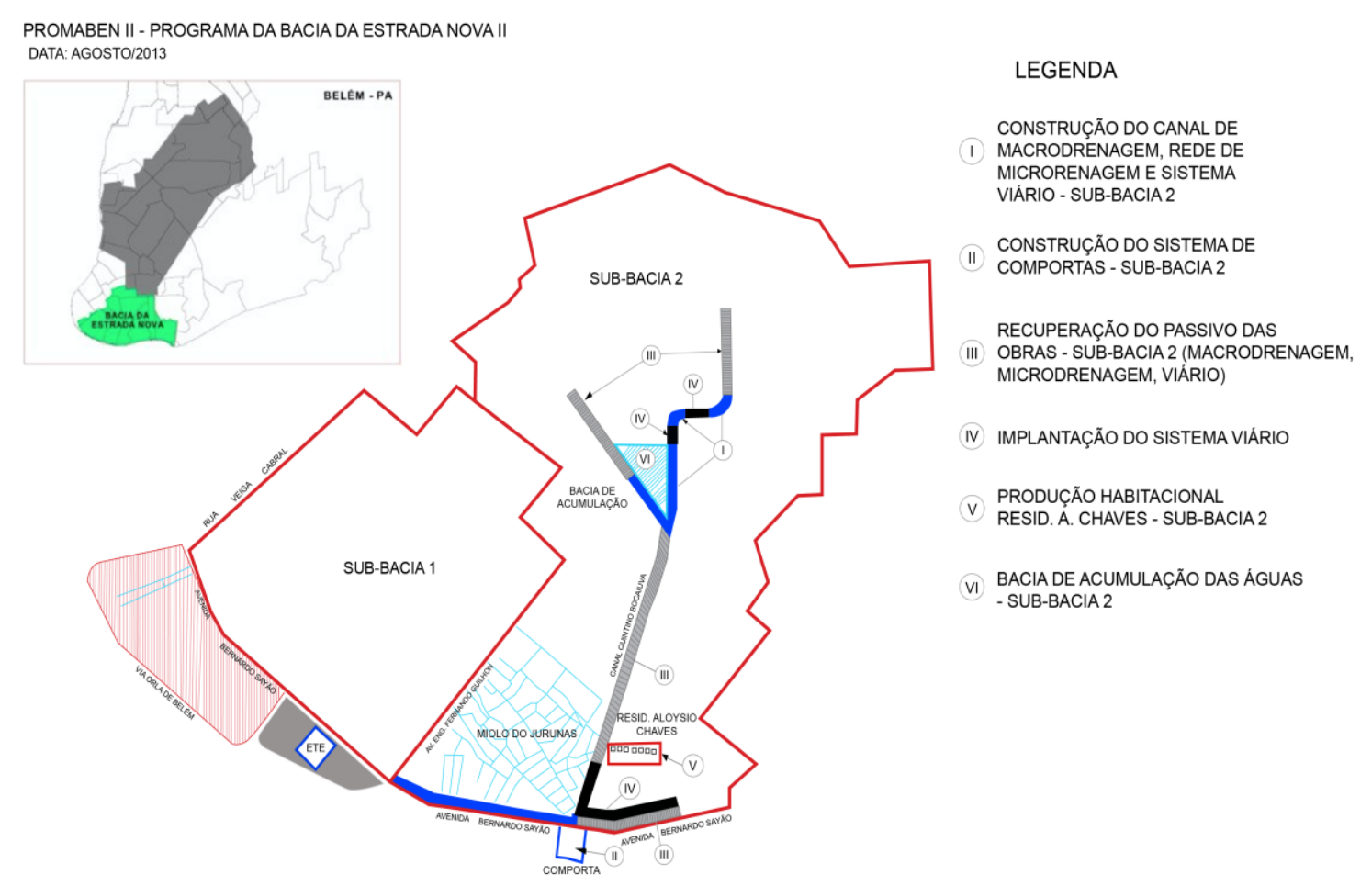

Fonte: ENGESOLO (2008)

\section{Aplicação do SWMM para a SB2}

Dadas às condições de uso, ocupação e impermeabilização do solo, adotou-se para a relação entre volume precipitado e volume escoado superficialmente o valor $\mathrm{C}=85 \%$. Os parâmetros gerais de cálculo foram:

a) Utilizou-se a fórmula de MANNING;

$$
\mathrm{V}=(\mathbf{1} / \mathbf{n}) \cdot \mathbf{R}^{\mathbf{2} / \mathbf{3}} \cdot \mathrm{D}^{\mathbf{1} / \mathbf{2}}
$$

\section{Onde:}

$\mathrm{V}=$ velocidade média na seção $(\mathrm{m} / \mathrm{s})$;

$\mathrm{n}=$ coeficiente de Manning;

$\mathrm{R}=$ raio hidráulico $(\mathrm{m})$;

$\mathrm{D}=$ declividade $(\mathrm{m} / \mathrm{m})$.

b) Considerou-se o Coeficiente de Rugosidade (n) para o concreto $(0,013)$ e para o canal em terra com grama $(0,033)$;

c) Declividade (i) $=0,001 \mathrm{~m} / \mathrm{m}(\%, 1$ por mil).

\section{Série Temporal}

Para a simulação da SB2, foram utilizados dados pluviométricos, de chuva intensa ocorrida no dia 09 de maio de 2011 em Belém do Pará, com precipitação total de $61 \mathrm{~mm}$ e duração de 3 horas, oriundos do Instituto Nacional de Meteorologia (INMET), conforme estudo desse evento climático real publicado por ARAÚJO et al.(2012), conforme Figura 5. 
Figura 5- Chuva intensa ocorrida no dia 09/05/ 2011.

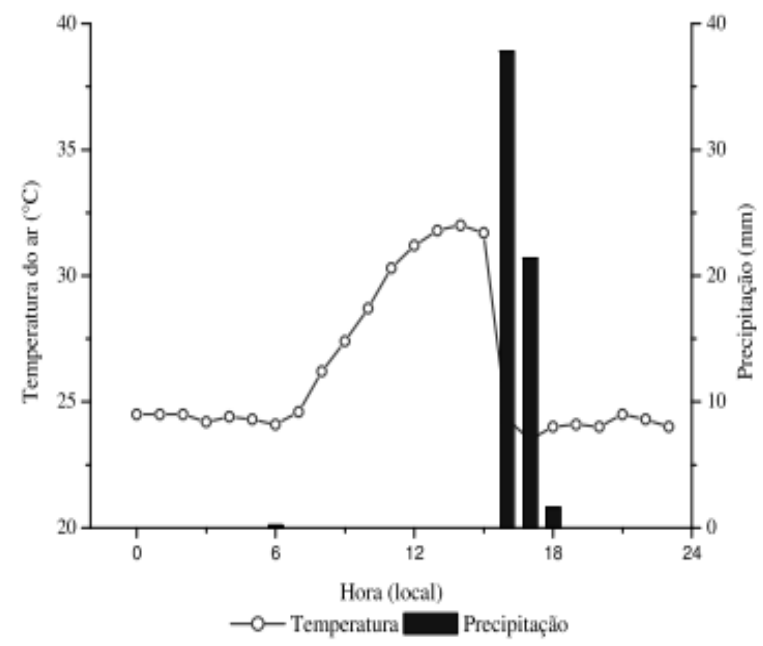

Fonte: Araújo et al. (2012)

A Figura 6 apresenta a série temporal da chuva intensa utilizada na simulação.

Figura 6 - Precipitação

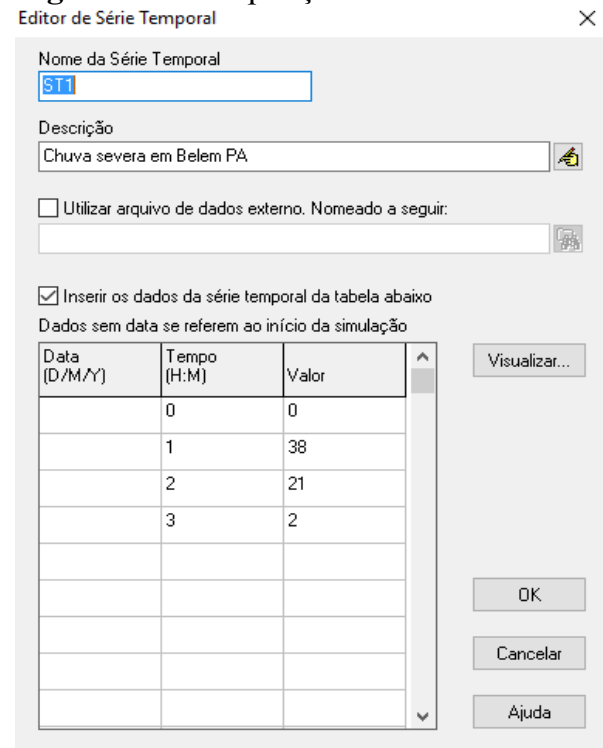

Fonte: CUNHA (2016)

\section{Curva de Maré}

A Figura 7 apresenta os dados da maré do dia e hora de ocorrência da chuva intensa utilizada na curva de maré no SWMM.
Figura 7 - Dados da curva de maré.

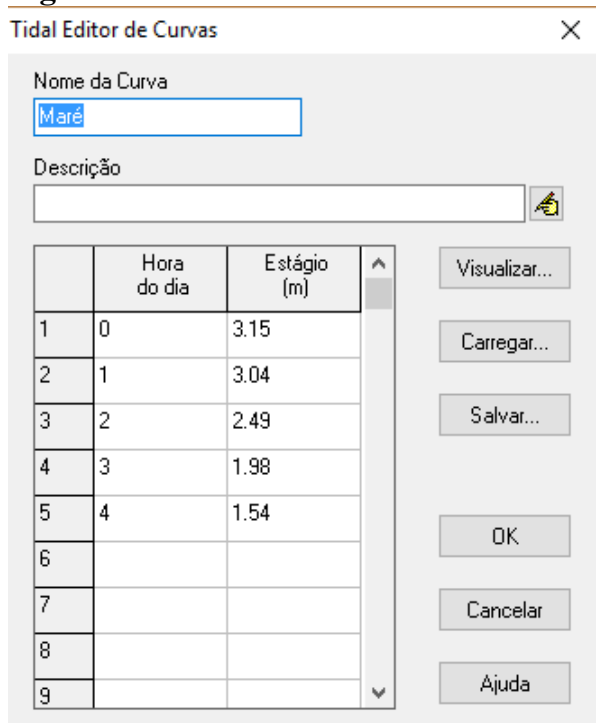

Fonte: CUNHA (2016)

\section{Dados do canal}

O canal principal apresenta comprimento de 3.300 metros, seção retangular a céu aberto, paredes revestidas em concreto armado, estroncas transversais, viga de coroamento longitudinal e declividade de $0,001 \mathrm{~m} / \mathrm{m}$.

\section{Discretização da SB2}

A área de drenagem da SB2 totalizou 404 ha, sendo considerada ocupação de 85 a 95\% das áreas urbanizadas.

Ressalta-se que devido à magnitude de sua área de drenagem (404 hectares) e a maior complexidade do seu sistema de macrodrenagem, a SB2 foi dividida em 18 sub-bacias, buscando a melhor representatividade das características naturais da bacia estudada.

A Tabela 1 apresenta os dados da SB2 utilizados para alimentar o programa e executar a simulação. 
Onde temos as seguintes definições:

$\mathrm{C}=$ Conduto;

$\mathrm{S}=$ Sub-bacia;

$\mathrm{E}=$ Exutório.

$\mathrm{J}=\mathrm{Junção}$;

Tabela 1 - Discretização da Sub-Bacia 2

\begin{tabular}{|c|c|c|c|c|c|c|c|c|c|c|}
\hline $\begin{array}{l}\text { Sub- } \\
\text { Bacia }\end{array}$ & $\begin{array}{c}\text { Área } \\
\text { (ha) }\end{array}$ & $\begin{array}{l}\text { Exu- } \\
\text { tório }\end{array}$ & Canal & $\begin{array}{c}\text { Trecho } \\
\text { Jusante }\end{array}$ & $\begin{array}{c}\text { Nós } \\
\text { Inicial e } \\
\text { Final } \\
\end{array}$ & $\begin{array}{l}\text { Exten- } \\
\text { são } \\
(\mathbf{m}) \\
\end{array}$ & $\begin{array}{c}\text { Base } \\
\text { (m) }\end{array}$ & $n$ & $\begin{array}{c}\text { Declivi- } \\
\text { dade } \\
(\%) \\
\end{array}$ & $\begin{array}{l}\text { Cota do } \\
\text { radier } \\
\text { (m) } \\
\end{array}$ \\
\hline $\mathrm{S} 1$ & 15 & $\mathrm{~J} 2$ & Av. Bernardo Sayão & $\mathrm{C} 2 \_\mathrm{E}$ & $\mathrm{J} 2 \_\mathrm{E}$ & 200 & 8,00 & 0,013 & 0,1 & 4,80 \\
\hline $\mathrm{S} 2$ & 40 & $\mathrm{~J} 3$ & $\begin{array}{l}\text { Tv. Quintino } \\
\text { Bocaiuva }\end{array}$ & C3_E & J3_E & 100 & 9,00 & 0,013 & 0,1 & 4,80 \\
\hline $\mathrm{S} 3$ & 35 & $\mathrm{~J} 4$ & $\begin{array}{l}\text { Tv. Quintino } \\
\text { Bocaiuva }\end{array}$ & C4_3 & J4_J3 & 100 & 9,00 & 0,013 & 0,1 & 4,80 \\
\hline $\mathrm{S} 4$ & 30 & J5 & $\begin{array}{l}\text { Tv. Quintino } \\
\text { Bocaiuva }\end{array}$ & C5_4 & J5_J4 & 100 & 9,00 & 0,013 & 0,1 & 4,80 \\
\hline S5 & 30 & J6 & $\begin{array}{l}\text { Tv. Quintino } \\
\text { Bocaiuva }\end{array}$ & C6_5 & J6_J5 & 100 & 9,00 & 0,013 & 0,1 & 4,80 \\
\hline S6 & 30 & $\mathrm{~J} 1$ & $\begin{array}{l}\text { Tv. Quintino } \\
\text { Bocaiuva }\end{array}$ & $\mathrm{C} 1 \_2$ & J1_J2 & 400 & 9,00 & 0,013 & 0,1 & 4,80 \\
\hline S7 & 30 & $\mathrm{~J} 8$ & $\begin{array}{l}\text { Tv. Quintino } \\
\text { Bocaiuva }\end{array}$ & C8_7 & J8_J7 & 100 & 9,00 & 0,013 & 0,1 & 4,80 \\
\hline S8 & 35 & $\mathrm{~J} 7$ & $\begin{array}{l}\text { Tv. Quintino } \\
\text { Bocaiuva }\end{array}$ & C7_6 & J7_J6 & 100 & 9,00 & 0,013 & 0,1 & 4,80 \\
\hline S9 & 30 & $\mathrm{~J} 10$ & $\begin{array}{l}\text { Tv. Quintino } \\
\text { Bocaiuva }\end{array}$ & C10_9 & J10_J9 & 100 & 9,00 & 0,013 & 0,1 & 4,80 \\
\hline S10 & 35 & J9 & $\begin{array}{l}\text { Tv. Quintino } \\
\text { Bocaiuva }\end{array}$ & C9_8 & J9_J8 & 100 & 9,00 & 0,013 & 0,1 & 4,80 \\
\hline S11 & 5 & $\mathrm{~J} 18$ & $\begin{array}{l}\text { Tv. Dr. Moraes - Tv. } \\
\text { Quintino Bocaiuva }\end{array}$ & C18_12 & $\mathrm{J} 18 \_\mathrm{J} 12$ & 200 & 6,00 & 0,033 & 0,1 & 4,80 \\
\hline S12 & 4 & $\mathrm{~J} 12$ & $\begin{array}{l}\text { Tv. Dr. Moraes - Tv. } \\
\text { Quintino Bocaiuva }\end{array}$ & C12_11 & J12_J11 & 150 & 8,00 & 0,013 & 0,1 & 4,80 \\
\hline S13 & 31 & J11 & $\begin{array}{l}\text { Tv. Quintino } \\
\text { Bocaiuva }\end{array}$ & C11_10 & J11_J10 & 100 & 8,00 & 0,013 & 0,1 & 4,80 \\
\hline S14 & 8 & J13 & $\begin{array}{l}\text { Av. Generalíssimo } \\
\text { Deodoro }\end{array}$ & C13_12 & J13_J12 & 150 & 9,00 & 0,013 & 0,1 & 4,80 \\
\hline S15 & 6 & $\mathrm{~J} 17$ & $\begin{array}{c}\text { Tv. Dr. Moraes - Av. } \\
\text { Generalíssimo } \\
\text { Deodoro }\end{array}$ & C17_18 & J17_J18 & 600 & 6,00 & 0,013 & 0,1 & 4,80 \\
\hline S16 & 20 & $\mathrm{~J} 15$ & $\begin{array}{c}\text { Av. Generalíssimo } \\
\text { Deodoro - R. dos } \\
\text { Caripunas } \\
\end{array}$ & C15_14 & J15_J14 & 200 & 9,00 & 0,013 & 0,1 & 4,80 \\
\hline $\mathrm{S} 17$ & 10 & $\mathrm{~J} 14$ & $\begin{array}{l}\text { R. dos Caripunas - } \\
\text { Tv. } 14 \text { de Março }\end{array}$ & C14_13 & J14_J13 & 300 & 14,25 & 0,013 & 0,1 & 4,80 \\
\hline S18 & 10 & $\mathrm{~J} 16$ & Tv. 14 de Março & C16_15 & J16 J15 & 200 & 7,00 & 0,013 & 0,1 & 4,80 \\
\hline
\end{tabular}

Fonte: CUNHA (2016).

\section{Mapa da área estudada}

A imagem da bacia estudada é mostrada na Figura 8 e foi obtida através do Google Earth.

\section{Adição de objetos}

Após a divisão em 18 sub-bacias, foram adicionados os objetos que constituem essa rede de macrodrenagem, consideradas as curvas de níveis da bacia.

Os objetos adicionados no mapa dos três cenários simulados (canal com projeto parcialmente executado; canal projetado e implantado sem bacia de acumulação; canal com projeto completamente implantado e com 
bacia de acumulação), são os seguintes: 1 medidor de chuva, 18 junções, 18 condutos, 1 nó de lançamento ou emissário e 1 unidade de armazenamento.
Assim, em cada objeto foram inseridos dados necessários para simulação, conforme mostrado na Figura 9.

Figura 8 - Sub-bacia 2 da Estrada Nova no SWMM

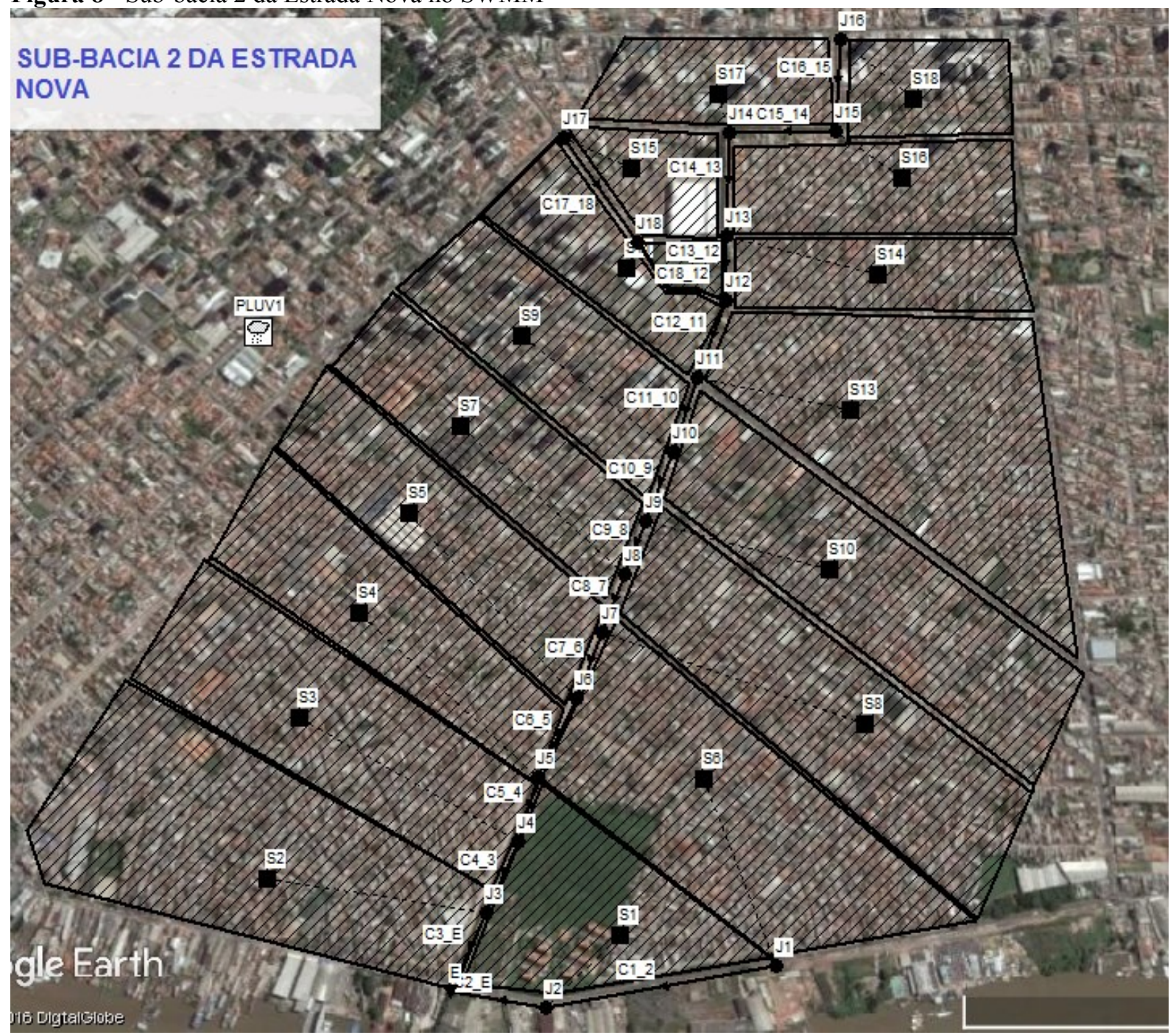

Fonte: Google Earth adaptado no SWMM (2016).

A Figura 9 mostra a SB2 no SWMM. 
Figura 9 - Sub-Bacia 2 da Estrada Nova no SWMM.

SWWMM 5 - SB2 ESTRADA NOVA TENT 1.inp

Arquivo Editar Visualizar Projeto Relatório Ferramentas Janela Ajuda

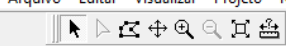

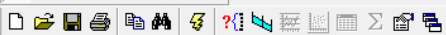

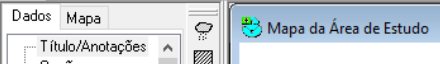

Opções

H. Hidrologia

Pluviômetros
Sub-bacias

Aquíferos

Hidrograma Uni

Controles LID

E. Hidrálica

Nós

- Exuexário

-. Unidades d

Trechos

Condutos
Bombas
Dombs

Orificios

+ - 刍

$+\hat{z} \downarrow$

Título/Anotaç̃es

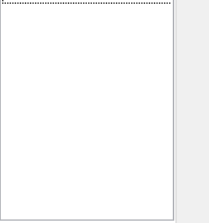

Auto-Compimento: Desativado - Offsets: Profundidade - Unidades de Vazão: LPS -

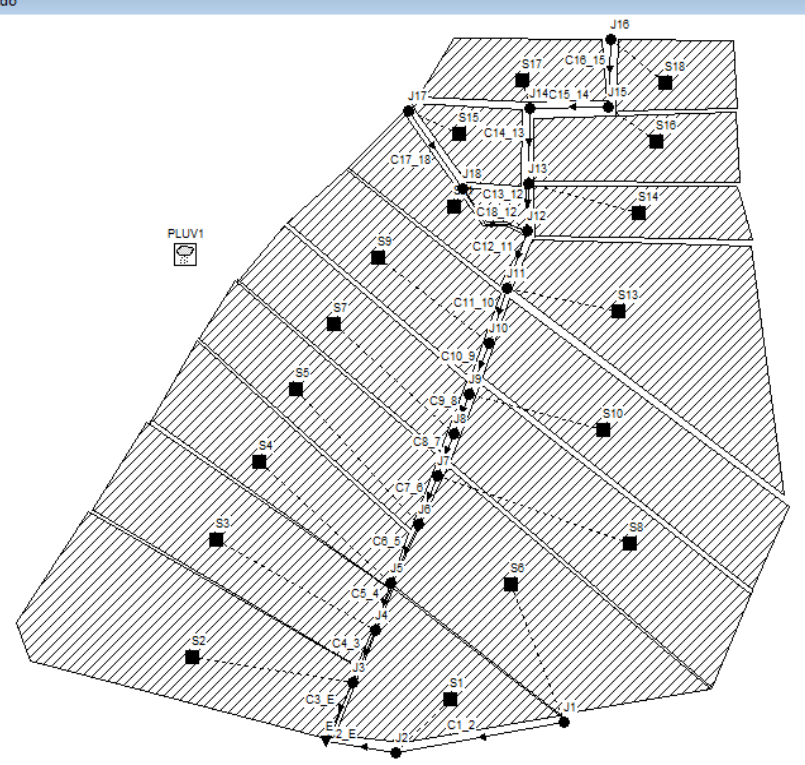

Fonte: CUNHA (2016).

\section{RESULTADOS E DISCUSSÃO}

Quando executada a simulação, o programa processa todos os dados que foram inseridos cautelosamente, afim de se gerar resultados com os menores erros possíveis. Assim, em seguida aparece uma janela exibindo informações da ocorrência de erros de escoamento superficial e propagação de vazão, caso a simulação tenha sido bem sucedida.

Foram realizadas simulações em três cenários diferentes, todas bem sucedidas, conforme figura 10, e que os resultados serão discutidos mais à frente. Como se pode observar abaixo, um dos resultados dos cenários, apresentando erro de $-0,11 \%$ de escoamento superficial e $-0,31$ de propagação de vazão.
Figura 10 - Resultado da simulação na rede de drenagem para o cenário 1

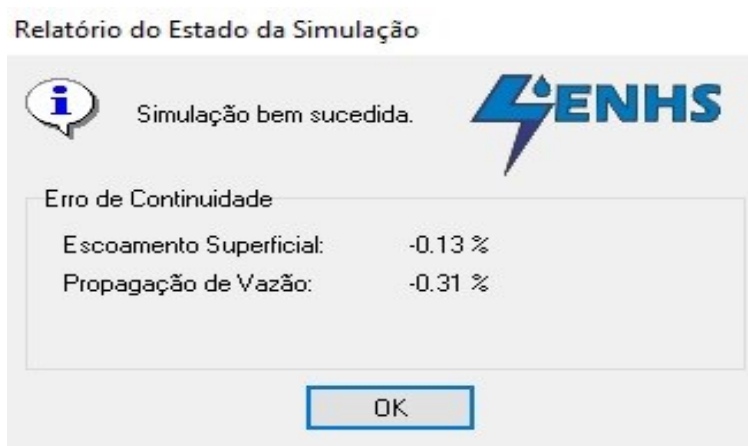

Fonte: CUNHA (2016)

Através do recurso animador gráfico da área de estudo, que mostra o perfil da cota do nível d'água, pode-se visualizar o comportamento do fluxo na rede, obtendo informações se houve enchente em algum trecho do sistema e em que instante ocorreu, para os canis e cenários estudados. 


\section{Cenário 1 - Canal atual.}

Para a simulação do cenário 1, considerou-se a situação atual, com cerca de 90\% dos canais executados. A Figura 11 mostra o canal da Tv. Quintino nesse cenário.
Observa-se que em $3 \mathrm{~h}$ de chuva houve transbordo entre as junções E a J6 e J11 a J12 do canal da Tv. Dr. Moraes. Os níveis maiores em todos os trechos foram alcançados em

Figura 11 - Canal da Tv. Quintino Bocaiuva.

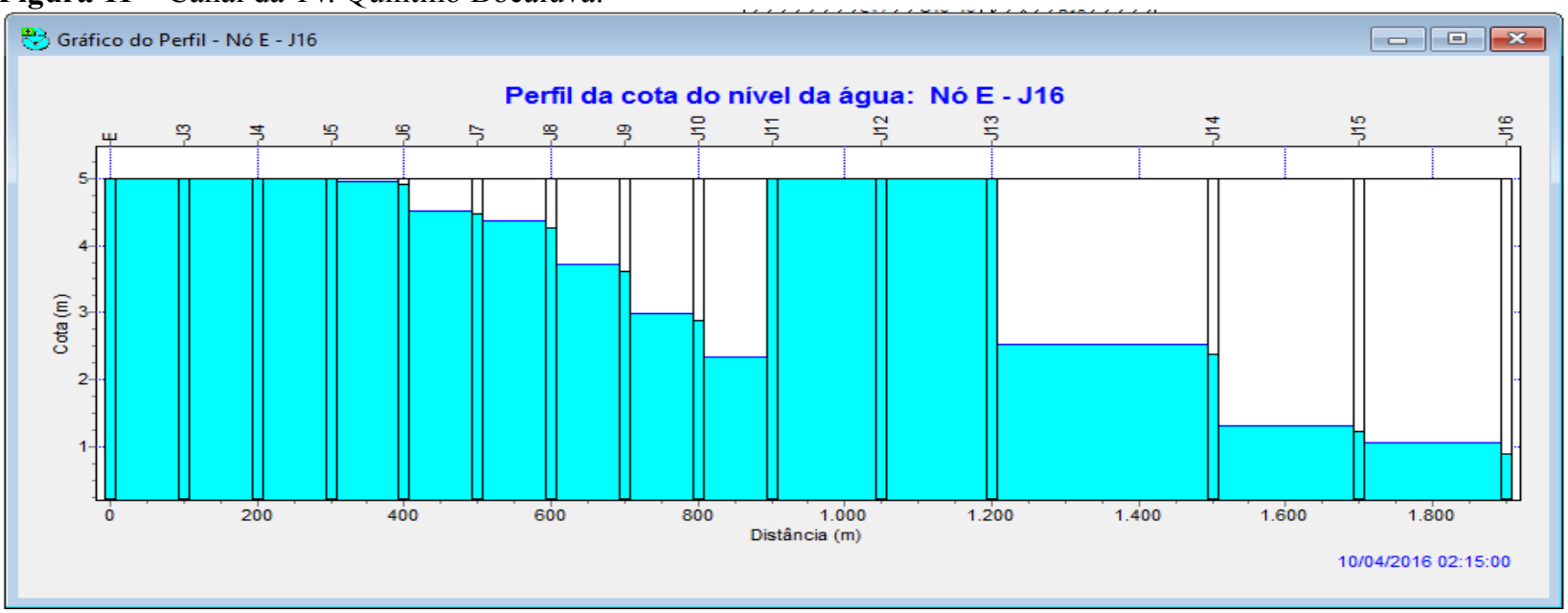

Fonte: CUNHA (2016).

Em 3 h de chuva houve transbordo entre junções E a J6 e J11 a J13 do canal da Tv. Quintino Bocaiúva. Os níveis maiores em todos os trechos foram alcançados em $2 \mathrm{~h}$ e 15 min de chuva, e começou a ocorrer transbordo a partir de 1h, entre as junções E a J6

A Figura 12 apresenta o canal da Tv.

Dr. Moraes no cenário 1- situação atual. 2h15min de chuva, e começou a ocorrer transbordo a partir de $1 \mathrm{~h}$, entre as junções $\mathrm{E}$ a J6.

\section{Cenário 2 - Canal projetado sem bacia de} acumulação.

Nessa simulação levou-se em consideração o canal projetado com as mesmas cotas, porém todo em concreto.

Figura 12 - Canal da Tv. Dr. Moraes.

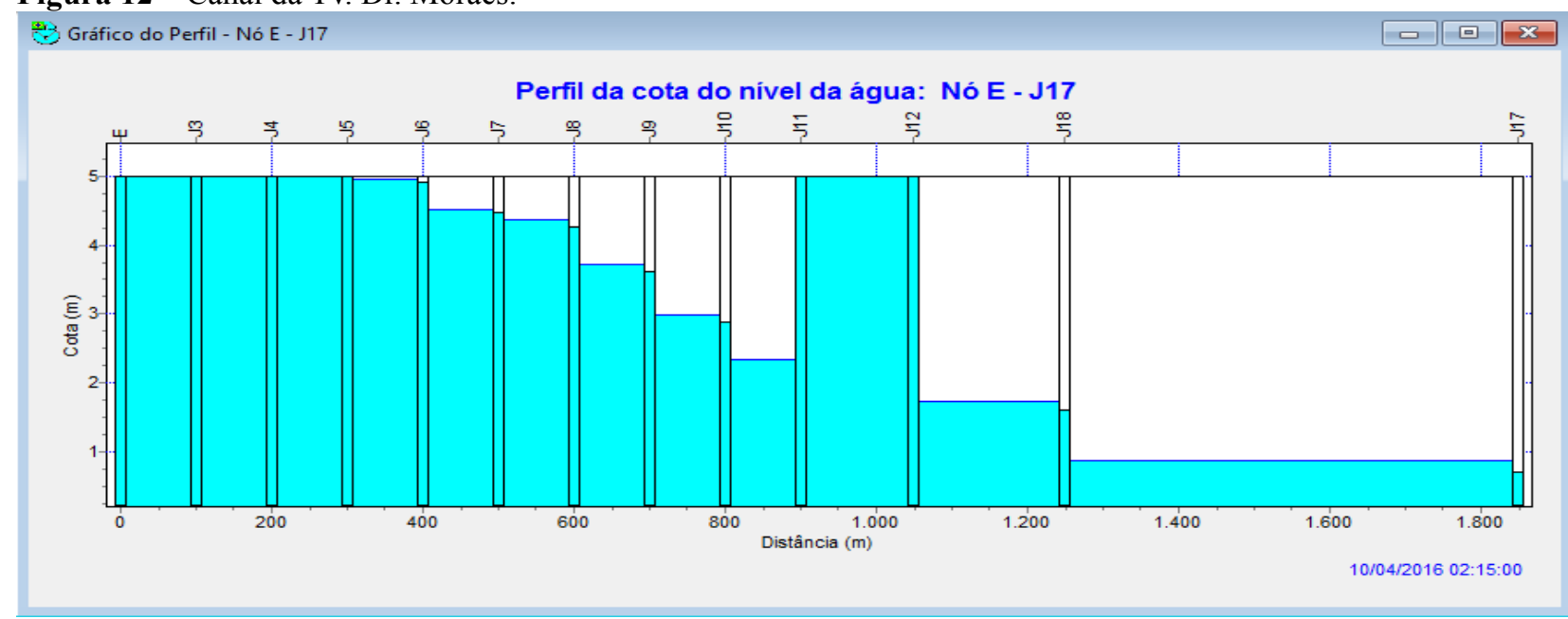

Fonte: CUNHA (2016). 
A Figura 13 apresenta o canal da Tv.

Quintino Bocaiúva no cenário 2 - canal projetado sem bacia de acumulação. 1h15min de chuva. Os maiores níveis na maioria dos trechos foram alcançados em $2 \mathrm{~h}$ de chuva.

Figura 13 - Canal da Tv. Quintino Bocaiuva.

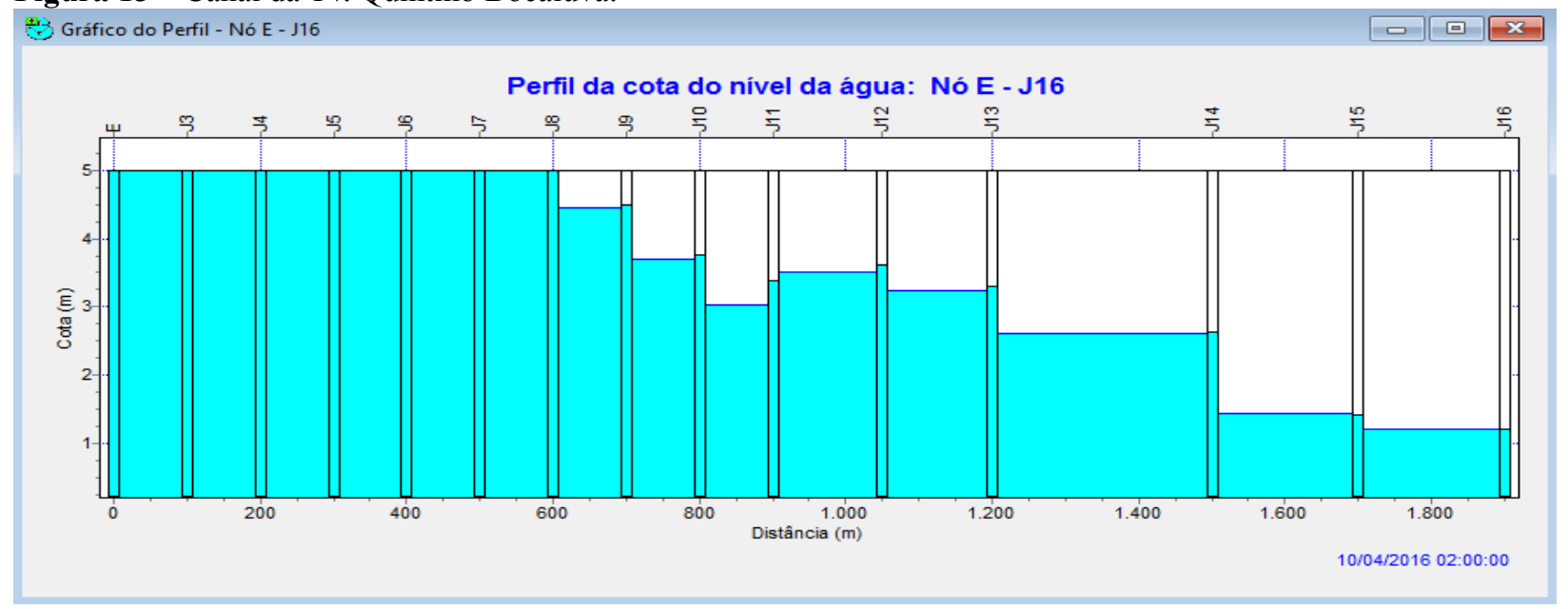

Fonte: CUNHA (2016).

Analisando a Tv. Quintino Bocaiúva, a Figura 13 mostra que em 3 h de chuva houve transbordo entre as junções $\mathrm{E}$ e $\mathrm{J} 8 \mathrm{em}$ 1h15min de chuva. Os maiores níveis na maioria dos trechos foram alcançados em $2 \mathrm{~h}$ de chuva.

A Figura 14 apresenta o canal da Tv. Dr. Moraes no cenário 2 - canal projetado sem bacia de acumulação.

\section{Cenário 3 - Canal projetado com bacia de} acumulação

Para essa simulação levou-se em consideração o canal projetado com as mesmas cotas, todo em concreto e com uma bacia de acumulação com área aproximadamente de $22.622 \mathrm{~m}^{2}$, ao redor dos trechos mais críticos quanto às enchentes.

A Figura 15 apresenta o canal da Tv.

Figura 14 - Canal da Tv. Dr. Moraes.

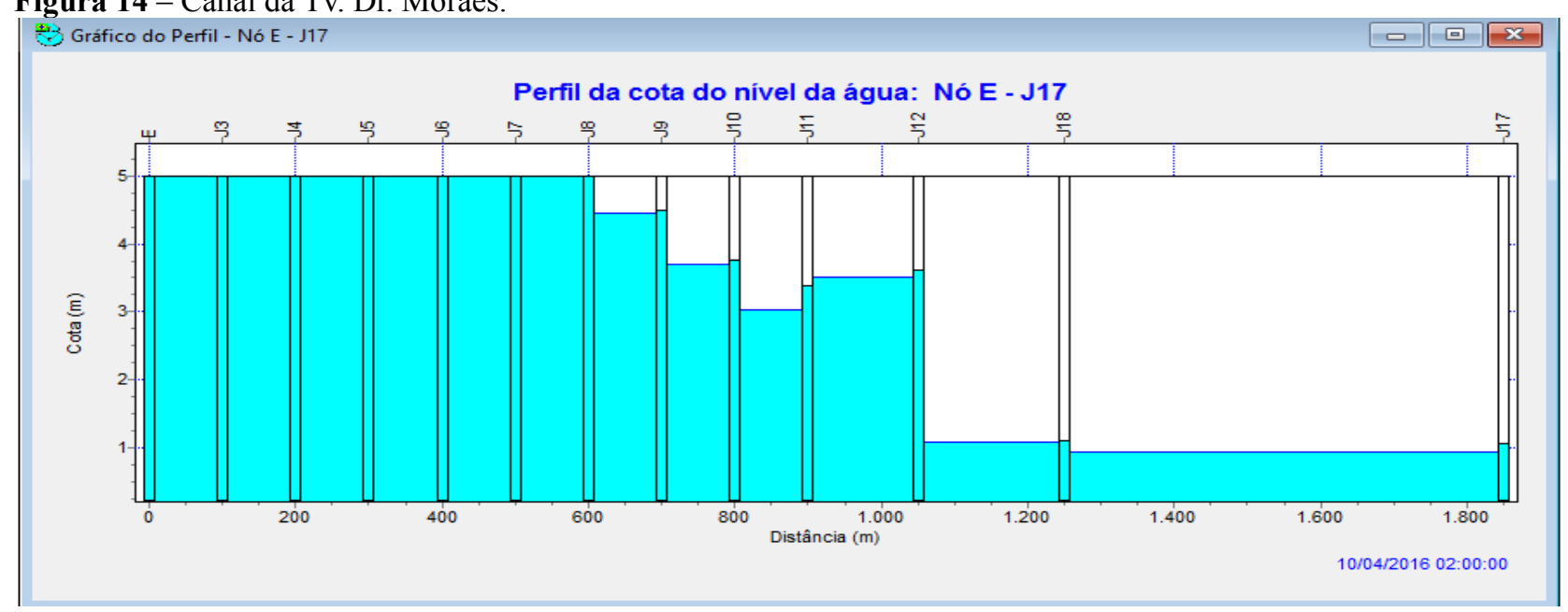

Fonte: CUNHA (2016).

Verifica-se que em $3 \mathrm{~h}$ de chuva houve transbordo entre as junções $\mathrm{E}$ e $\mathrm{J} 8 \mathrm{em}$
Quintino Bocaiúva para o cenário 3 - canal projetado com bacia de acumulação. 
Figura 15 - Canal da Tv. Quintino Bocaiuva

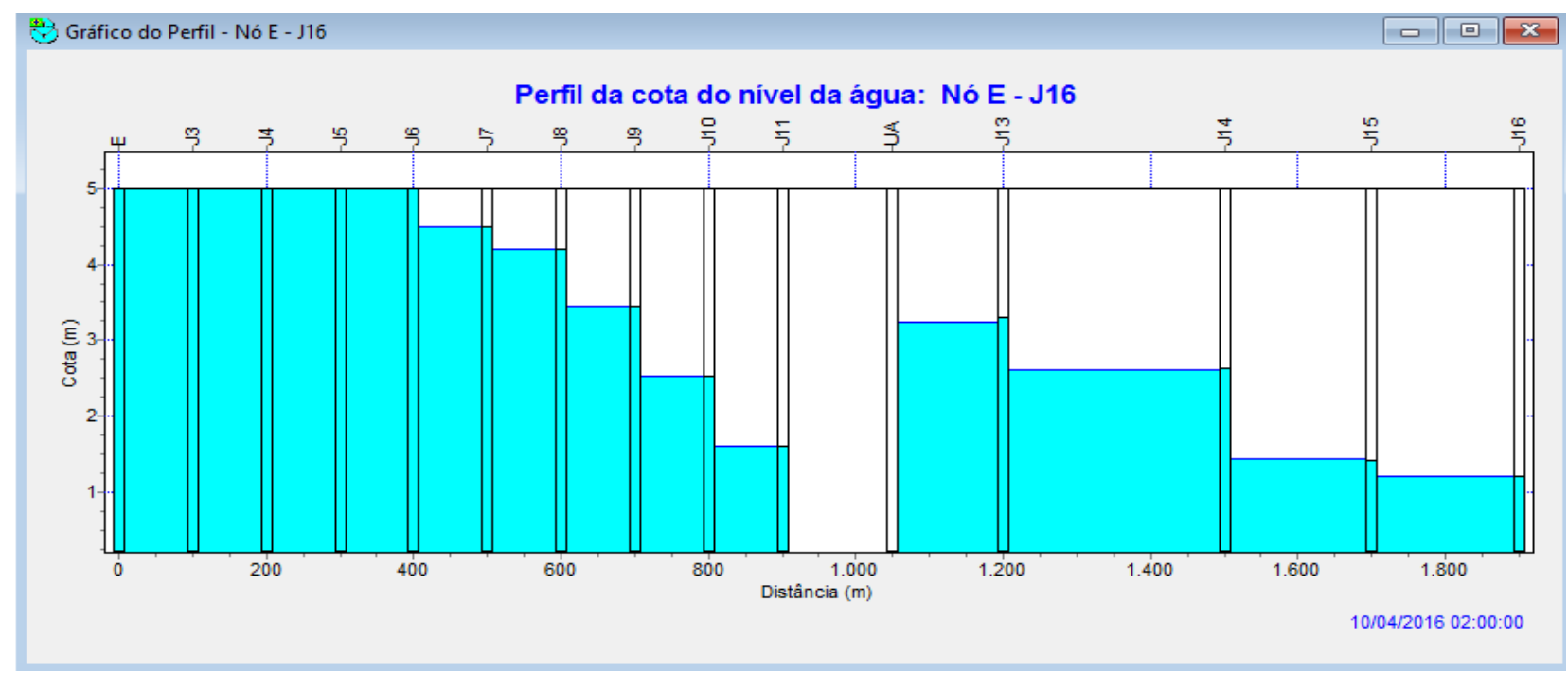

Fonte: CUNHA (2016)

Mostra-se que em $3 \mathrm{~h}$ de chuva, houve transbordo entre junções E a J6. Os maiores níveis na maioria dos trechos foram alcançados em $2 \mathrm{~h}$ de chuva.

A Figura 16 mostra o canal da Tv.

Dr. Moraes para o cenário do canal projetado com bacia de acumulação.

Figura 16 - Canal da Tv. Dr. Moraes

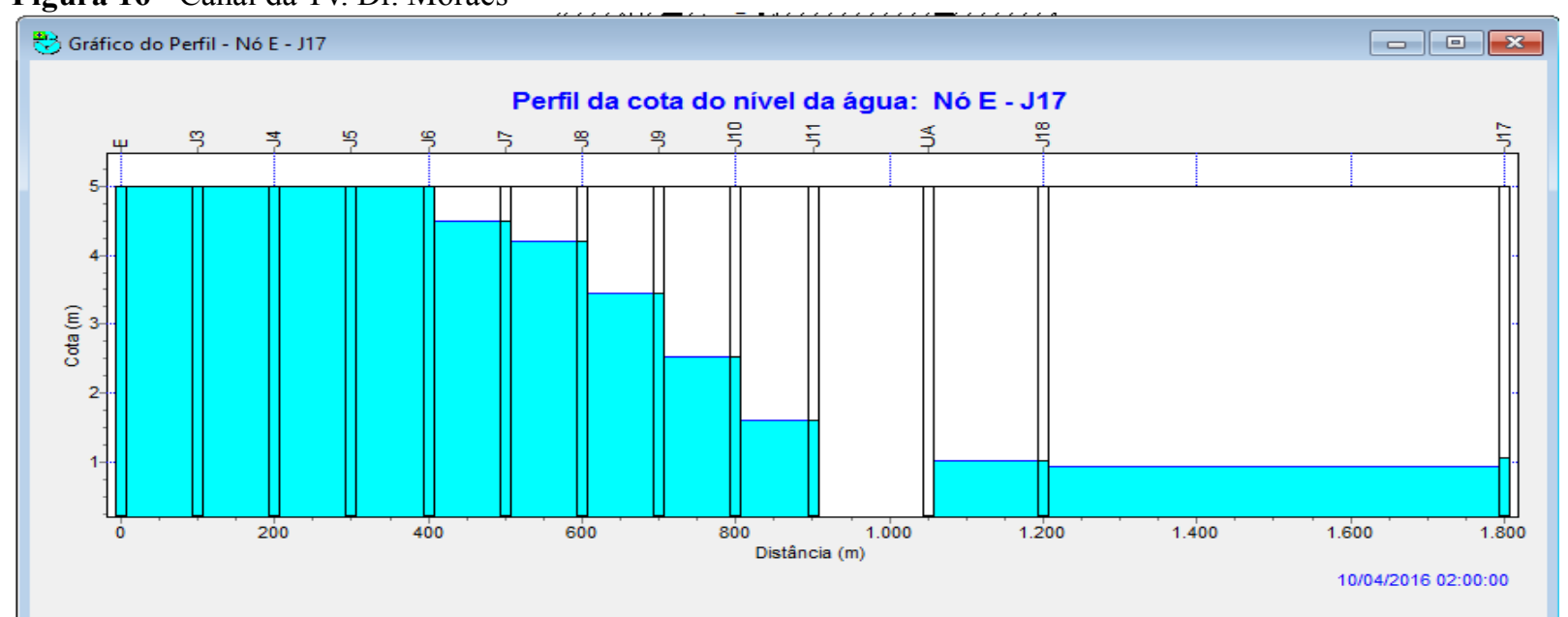

Fonte: CUNHA (2016)

Mostra-se que em $3 \mathrm{~h}$ de chuva, houve transbordo entre junções E a J6. Os maiores níveis na maioria dos trechos foram alcançados em $2 \mathrm{~h}$ de chuva.

\section{CONCLUSÃO}

O programa possibilitou simular-se e estudar-se o escoamento superficial da Subbacia 2 (SB2) da Estrada Nova e analisar-se as possibilidades de alagamento nos pontos críticos do canal, visto que o mesmo recebe as 
variantes de maré cheia ou vazia com picos de cheias durante as estações de chuva intensa nos primeiros meses do ano, de janeiro a maio.

$\mathrm{Na}$ avaliação do comportamento da bacia foram analisados três cenários diferentes: da situação atual que se encontra hoje, com inicialização dos projetos, porém incompletos em várias partes do percurso, não resolvendo os problemas da SB2; a situação caso fosse finalizado o projeto como proposto, porém sem bacia de acumulação, ainda resultou em enchentes nos pontos críticos; e a situação caso fosse realizado o projeto completo, inclusive com a localização e o volume sugerido da bacia de acumulação, na qual teria o objetivo de suportar melhor um evento crítico de chuva, ainda assim não foi a solução para o problema de enchentes, visto que ainda ocorreria transbordamento.

Diante dos resultados apresentados nos três cenários, a rede de macrodrenagem de nenhum deles suportaria sem transbordar o evento estudado. Porém, em relação a atual situação o canal projetado, apresenta melhoria no escoamento, e se dotado de bacia de acumulação menor ainda se tornaria $o$ alagamento, o qual, entretanto ainda ocorreria, mostrando a utilidade do uso do SWMM para auxiliar nesse estudo.

Observou-se que as junções mais críticas em que ocorreriam enchentes, mesmo com as alterações em projeto e a bacia de acumulação, seriam J1, J2, J3, J4, J5 e J6, com todas tendo influência do canal da TV. Quintino Bocaiuva e do exutório a jusante da mesma, que faz encontro com a Av. Bernardo Sayão. Ou seja, um dos pontos a serem verificados e alterados seria a área da bacia de acumulação, necessitando de uma maior dimensão, a fim de suprir o volume precipitado e fazendo com que não transborde nas junções seguintes.

Logo, pode-se perceber que a simulação da bacia gera importantes informações para o entendimento dos processos do sistema de drenagem urbana, mostrando em gráficos que o canal independentemente da situação atual ou projetada, não atende as demandas de contribuições das sub-bacias, acarretando problemas para uma intensidade pluviométrica de $61 \mathrm{~mm}$ em intervalo de tempo de três horas, conciliando-a com a entrada de maré no canal.

Desse modo, pode-se analisar que os modelos hidrológicos são ferramentas importantes para o gerenciamento e planejamento da drenagem pluvial na cidade de Belém, ou em qualquer outra, possibilitando a verificação dos possíveis impactos produzidos pela urbanização com um crescimento desordenado e principalmente em áreas frágeis, ocasionando diversos danos.

Uma das contribuições do presente trabalho cientifico foi dar continuidade aos estudos realizados com o programa SWMM, reforçando o quão útil e significante é esta ferramenta, podendo ser utilizada com diversos objetivos, possibilitando um melhor 
planejamento de sistema de drenagem nas cidades, facilitando a vida da sociedade e contribuindo para um melhor cenário.

Sugere-se para pesquisas futuras que seja realizada a simulação hidrológica no programa SWMM, sendo adotados os mesmos dados, como índice pluviométrico e entrada de marés, em outras bacias hidrográficas na região metropolitana de Belém, para que possa servir de base de pesquisa e estudo no desenvolvimento e implantação de novos projetos, tornando-os cada vez mais eficazes.

\section{REFERÊNCIAS}

ARAÚJO, S.R.V.; SANTOS, A.P.P.; REIS, J.S. \& ROCHA, E.J.P. Precipitação severa em Belém do Pará: estudo de caso. In Anais XVII Congresso Brasileiro de Meteorologia - CBMET. Belém: CBMET, 2012.

ARAÚJO, C.L.C. et al. Ocupação e Consolidação das Baixadas em Belém-PA: periferia e Portal da Amazônia. In: Anais do Seminário Nacional sobre Áreas de Preservação Permanente em Meio Urbano. Natal, 2012.

ARAÚJO JR, A.C.R. Planejamento urbanoambiental na cidade de Belém (PA): reflexões sobre o PROMABEN. Desenvolvimento e Meio ambiente, v. 27. Paraná: Editora UFPR, 2013.

BRASIL, S.C. Projeto de Macrodrenagem da Bacia do Una e índice de qualidade de vida dos seus moradores. Dissertação (Mestrado em Engenharia Civil). UFPA: Belém, 2004.

Constituição Federal. Constituição da República Federativa do Brasil. Brasília, DF: Senado 1988.
CUNHA, M. A. Aplicação do simulador hidrológico storm water management model (SWMM) na Sub-bacia 2 da Estrada Nova-Belém/PA. 2016. $48 \mathrm{f}$. Trabalho de Conclusão de Curso (Bacharel em Engenharia Sanitária e Ambiental) - Centro de Ciências Exatas e Tecnologia, Universidade da Amazônia, Belém.

ENGESOLO ENGENHARIA LTDA. Prefeitura Municipal de Belém. Elaboração de estudos e projetos básicos necessários à preparação do programa de macrodrenagem da Bacia da Estrada Nova - PROMABEN. Belo Horizonte, 2008.

Google Earth. 2016. Disponível em: $<$ https://www.google.com.br/intl/ptBR/earth/>. Acesso em 10 de outubro de 2016.

Google Earth. 2017. Disponível em: $<$ https://www.google.com.br/intl/ptBR/earth/>. Acesso em 08 de maio de 2017.

LIMA, H.N.S. Estudo da conceituação e implementação de vias sanitárias em Belém: o caso da bacia de drenagem Estrada Nova. Dissertação (Mestrado em Engenharia Civil) - UFPA: Belém, 2004.

PIRES, A.M; MACEDO, A.L. Análise comportamental do dispositivo de macro drenagem implantado na sub bacia 01 da bacia estrada nova, Belém-Pará: canal em galeria de concreto pré-moldado seção retangular com uso de ferramenta computacional - SWMM. Belém, 2011.

RIGHETTO, A.M (Cord.). Manejo de águas pluviais urbanas. Rio de Janeiro: ABES, 2009.

ROSSMAN, L.A. Storm Water Management Model, Version 5.0: User's Manual. U.S. Environmental Protection Agency, Cincinnat. OH, 2007.

São Paulo (cidade). Secretaria Municipal de Desenvolvimento Urbano (SMDU). Manual de drenagem e manejo de águas pluviais: 
Sustentare, Três Corações, v. 1, n. 1, p. 1-17, ago./dez. 2017

gerenciamento do sistema de drenagem

urbana. São Paulo: SMDU, 2012.

TUCCI, C.E.M; MARQUES, D.M.L.M. (org.). Avaliação e controle da drenagem

urbana. Porto Alegre: Editora UFRGS, 2000.

TUCCI, C.E.M. Gestão de Drenagem Ur-

bana. Brasília, DF: CEPAL. IPEA, 2012. 